Review

\title{
Molecular Pathogenesis of Neuromyelitis Optica
}

\section{Wajih Bukhari ${ }^{1,2, *}$, Michael H Barnett ${ }^{3}$, Kerri Prain ${ }^{4}$ and Simon A Broadley ${ }^{1,2}$}

1 School of Medicine, Gold Coast Campus, Griffith University, QLD 4222, Australia; E-Mail: simon.broadley@griffith.edu.au

2 Department of Neurology, Gold Coast Hospital, Southport, QLD 4215, Australia

3 Brain and Mind Research Institute, Camperdown, NSW 2050, Australia;

E-Mail:michael@sydneyneurology.com.au

4 Autoimmune laboratory, Division of Immunology, Pathology Queensland, Herston, QLD 4029, Australia; E-Mail: kerri_prain@health.qld.gov.au

* Author to whom correspondence should be addressed; E-Mail: w.bukhari@griffith.edu.au; Tel.: +61-07-5678-0702; Fax: +61-07-5678-0708.

Received: 3 August 2012; in revised form: 8 September 2012 / Accepted: 13 September 2012 / Published: 11 October 2012

\begin{abstract}
Neuromyelitis optica (NMO) is a rare autoimmune disorder, distinct from multiple sclerosis, causing inflammatory lesions in the optic nerves and spinal cord. An autoantibody (NMO IgG) against aquaporin-4 (AQP4), a water channel expressed on astrocytes is thought to be causative. Peripheral production of the antibody is triggered by an unknown process in genetically susceptible individuals. Anti-AQP4 antibody enters the central nervous system (CNS) when the blood brain barrier is made permeable and has high affinity for orthogonal array particles of AQP4. Like other autoimmune diseases, Th17 cells and their effector cytokines (such as interleukin 6) have been implicated in pathogenesis. AQP4 expressing peripheral organs are not affected by NMO IgG, but the antibody causes extensive astrocytic loss in specific regions of the CNS through complement mediated cytotoxicity. Demyelination occurs during the inflammatory process and is probably secondary to oligodendrocyte apoptosis subsequent to loss of trophic support from astrocytes. Ultimately, extensive axonal injury leads to severe disability. Despite rapid advances in the understanding of NMO pathogenesis, unanswered questions remain, particularly with regards to disease mechanisms in NMO IgG seronegative cases. Increasing knowledge of the molecular pathology is leading to improved treatment strategies.
\end{abstract}


Keywords: pathogenesis; Devic's disease; immunology; genetics; neuromyelitis optica; multiple sclerosis; aquaporin-4; astrocytopathy; astrocyte

\section{Introduction}

A syndrome of severe demyelination affecting the optic nerves and spinal cord specifically was described in the mid-late 19th century by Allbutt and Erb [1,2] and possibly even earlier by others [3]. More detailed phenotypic features, including simultaneous, sequential and relapsing-remitting forms of the ocular and spinal manifestations together with detailed pathological studies were provided by Devic [4]. Whilst further phenotypic clues emerged over the following century, including cerebrospinal fluid (CSF) pleiocytosis, elevated CSF protein and normal magnetic resonance imaging (MRI) brain $[5,6]$, the clinical description of neuromyelitis optica (NMO) and the potential overlap with MS remained essentially unchanged until the discovery of a specific antibody (NMO IgG) in 2004 [7].

Table 1. Comparison of neuromyelitis optica (NMO) with multiple sclerosis (MS).

\begin{tabular}{ccc}
\hline Clinical feature & NMO & MS \\
\hline Optic neuritis & +++ & ++ \\
Severe, bilateral & ++ & $(+)$ \\
Myelitis & +++ & ++ \\
Partial & $(+)$ & +++ \\
Extensive $(>3$ segments) & +++ & -
\end{tabular}

CSF analysis

Oligoclonal bands

Elevated protein

$(+) \quad++$

Pleiocytosis

Lymphocytes

MRI brain

Normal at onset

Hypothalamic/thalamic

Large hemispheric

Brainstem

"Barkhof" abnormal MRI

NMO IgG

$+\quad(+)$

$++$

$++$

Gender ratio (F:M)

$\begin{array}{cc}++ & + \\ + & - \\ + & + \\ + & + \\ + & +++ \\ ++ & (-) \\ 9: 1 & 3: 1\end{array}$

-: never seen; (+): can be seen but rare; +: sometimes seen; ++: often seen; +++: essentially universal.

The clinical features of NMO are compared with MS in Table 1. NMO is characterised clinically by synchronous or sequential optic neuritis and longitudinally extensive spinal cord inflammation. Monophasic and relapsing courses are recognised; progressive disease is uncommon [8,9]. NMO is typically more severe than MS and is more likely to result in significant residual loss of vision and immobility following attacks $[6,10]$. MRI of the brain is typically normal initially and the CSF shows elevated protein and a lymphocytic pleiocytosis [6]. Oligoclonal bands are less commonly seen in NMO than in MS [11]. Since the discovery of NMO IgG the phenotype associated with NMO has 
broadened to include an encephalopathic presentation (sometimes with large diffuse cerebral white matter lesions) [12-14], recurrent optic neuritis or cord disease (including partial cord lesions) [14,15], intractable hiccups (particularly in childhood) [16,17] and an acute brain stem syndrome [17]. In addition to optic nerve involvement with or without nonspecific white matter lesions [6,13], other abnormalities found on brain MRI include lesions of the hypothalamus [12], periaqueductal grey matter [12,18] and splenium of the corpus collosum [19]. Confluent periventricular lesions are also rarely observed, mostly in fulminant cases [20,21]. The gender ratio for NMO is much higher (female:male $=9: 1$ ) [10] than it is for MS (3:1) [22]. An association with other autoimmune diseases has been frequently reported [23], in contrast with MS, which either does not show any association [24,25] or only a mild association with systemic autoimmunity [26,27].

Formal diagnostic criteria have been established for NMO [13]. Whilst a number of different diagnostic criteria have been proposed the most widely accepted require the presence of optic neuritis, acute myelitis and at least two out of: (1) contiguous spinal cord MRI lesion extending over $\geq 3$ vertebral segments; (2) brain MRI not meeting diagnostic criteria for multiple sclerosis; and (3) NMO IgG seropositive status [13]. Using these criteria, NMO IgG is found to be highly specific for NMO. However, these criteria do not capture a large number of cases that have an incomplete clinical picture. This includes cases of isolated or recurrent optic neuritis, isolated myelitis and more recently cases of recurrent hiccoughs in childhood, an acute brainstem syndrome, encephalitis involving the white matter and other unusual presentations which have been associated with NMO IgG and have been collectively labelled as NMO spectrum disorder [14].

As a seemingly antigen specific autoimmune disease with potentially dire consequences, treatment approaches in NMO are generally more aggressive than in MS and usually incorporates immunosuppressive therapy. There is increasing evidence that conventional treatment for MS, in the form of $\beta$-interferon, may be associated with a worse outcome in NMO [28-30]. Initial treatment of attacks in NMO is usually with high dose intravenous corticosteroids [6] or if this fails plasmapheresis [31]. Maintenance treatment with oral corticosteroids and immunosuppression (cyclophosphamide, azathioprine, mycophenolate mofetil, methotrexate) is recommended as first line treatment [32]. There is growing evidence for the role of rituximab therapy in NMO [33,34]. This treatment approach makes logical sense given the presumed pathogenic role of NMO IgG.

The discovery of NMO IgG, which is directed against aquaporin-4 (AQP4), has dramatically changed the clinical definition of NMO and our understanding of the pathophysiology of this disease. A picture is finally emerging of NMO as a distinct pathological entity rather than a variant of MS, although some areas of confusion remain.

In NMO, involvement of the optic nerves and the central grey matter of the spinal cord is common and may lead to severe loss of vision, disability and even death [6]. The brain is often relatively spared in the early stages of the disease [6]. The central pathological process in NMO is the production of abnormal auto-antibodies against AQP4 expressed on astrocytes. These autoantibodies mediate complement dependent necrosis of astrocytes [35] and subsequent demyelination [36] together with significant loss of neurons [37]. The aim of this review is to summarise the roles played by key molecules in the pathogenesis of NMO. The nexus between the molecular basis of NMO and potential therapeutic approaches will be explored. 


\section{Pathogenesis of NMO}

\subsection{Aquaporin 4}

Aquaporins are water channels present on cell membranes [38]. Of 13 different aquaporins, AQP4 is the predominant type found in mammalian brain [39]. The AQP4 gene is located on chromosome 18. The gene product is a bidirectional, osmosis driven water channel mainly expressed on the foot processes of astrocytes and on ependymal cells in the CNS [40]. It is also expressed in many other organs such as the kidneys, and the gastrointestinal and respiratory tracts [41]. In the CNS AQP4 is preferentially expressed in the retina [42], optic nerve, hypothalamus, cerebellum, periventricular and periaqueductal regions, and the spinal cord [40], and low levels are observed in the cerebral cortex [40,43]. AQP4 forms as a tetramer [44] and each AQP4 monomer has two splicing isoforms identified as M1 and M23. M1 (32 kDa) is 22 amino acids longer than M23 (30 kDa) which is spliced in a shorter formation at the $N$-terminus [45]. M23 is the predominant isoform in the CNS [46]. AQP4 tetramers are arranged in groups in the form of orthogonal arrays of particles (OAP) on the cell membrane. The size and conformation of these arrays is determined by the relative amount of M23 versus M1 present in the tetramers [47]. AQP4 OAPs have been likened to rafts. The M1 isoform limits the size of OAPs but M23 facilitates formation of larger aggregates [48]. Post translationally, palmitic acid binds with $N$-terminal cysteines of M1 and inhibits orthogonal array formation [49]. AQP4 is associated with the glutamate transporter, excitatory amino acid transporter 2 (EAAT2). In AQP4-transfected cells, EAAT2 is internalised during AQP4 endocytosis [50,51], a process that has not been observed in primary astrocyte cultures or in vivo experiments [52].

AQP4 knockout mice do not show any neurological deficits in health [53] but show altered response in disease states. For example, AQP4 knockout mice show reduced cytotoxic oedema of the brain in stroke [53], reduced glial scar formation [54], increased vasogenic oedema with brain tumours [55] and CNS infection [56], and a more severe form of induced hydrocephalus [56].

\section{2. $N M O \operatorname{Ig} G$}

Antibodies against AQP4, originally identified as $\mathrm{NMO} \mathrm{IgG}$, were first demonstrated through standard immunofluorescence techniques using various substrates, including mouse brain and kidney [7]. Classical staining of the subpial surface, microvessels of brain and cerebellum and papillary tubules of the kidney is illustrated in Figure 1. Subsequently enzyme linked immunosorbent assay (ELISA) and live cell-based assays have been developed with live cell-based assays utilising the M23 isoform of AQP4 having the highest sensitivity [57].

NMO IgG has high specificity (99\%) [58,59] and moderate sensitivity ranging from 56\% [58] to $73 \%$ [7,58] for NMO. It has been observed that the sensitivity of the autoantibody is higher in relapsing cases of NMO [58]. The autoantibody in the blood of NMO patients is predominantly the IgG1 isotype (98\% of cases) [60], which can potently activate the complement system [61]. IgG2, IgG3 and IgG4 also occur in a lower proportion of cases [60]. IgM NMO antibody has also been reported in the blood of up to $10 \%$ of patients with NMO but it is not known to exist in the absence of $\operatorname{IgG}$ [62]. NMO IgG binds to the third extracellular loop of AQP4 [63] and the generation of conformational epitopes during OAP formation results in preferential binding with the M23 isoform [64]. One study 
has suggested that NMO IgG has considerably lower affinity for the AQP4 protein when compared with the epitope presented by OAPs [65]. NMO IgG does not cross the blood brain barrier (BBB) in normal subjects [66] but it can cross the placenta [67]. It has been demonstrated that NMO $\operatorname{IgG}$ is synthesised outside of the CNS. Persistent intrathecal synthesis of oligoclonal IgG, the most stable laboratory feature of MS, was absent in a study of 89 seropositive patients with NMO spectrum disorder, although transient intrathecal production was occasionally observed during acute relapses [11]. CSF from $20 \mathrm{NMO}$ patients showed lower titres of NMO IgG in CSF than in serum (with a ratio of 1:500) in keeping with extrathecal synthesis of the autoantibody [68]. A further seven cases of NMO with low CSF antibody index of NMO IgG (AQP4 IgG/Total IgG) have since been reported [69]. In order to cause disease in the CNS, the extrathecally produced autoantibody requires disruption of the BBB (possible mechanisms for this are discussed below). NMO IgG is occasionally restricted to the CSF [70] and AQP4 specific B cells have been identified in the CSF of one patient with NMO [71]. In some patients, NMO IgG is produced by a subset of CD20 negative B cells $\left(\mathrm{CD} 19^{\text {intermediate }} \mathrm{CD} 27^{\text {high }} \mathrm{CD} 38^{\text {high }} \mathrm{CD} 180^{-}\right)$that resembled early plasma cells [72].

Figure 1. NMO positive Immunofluorescence on a composite of mouse cerebellum, midbrain and kidney (serum dilution 1:40, goat anti-human $\operatorname{IgG} F(a b) 2$ fluorescein isothiocyanate, 200× magnification). (a) and (b) staining of subpial surface and microvessels of the midbrain. (c) Microvessel staining of cerebellar granular layer, molecular layer and white matter. (d) Staining of the papillary tubules of the kidney.

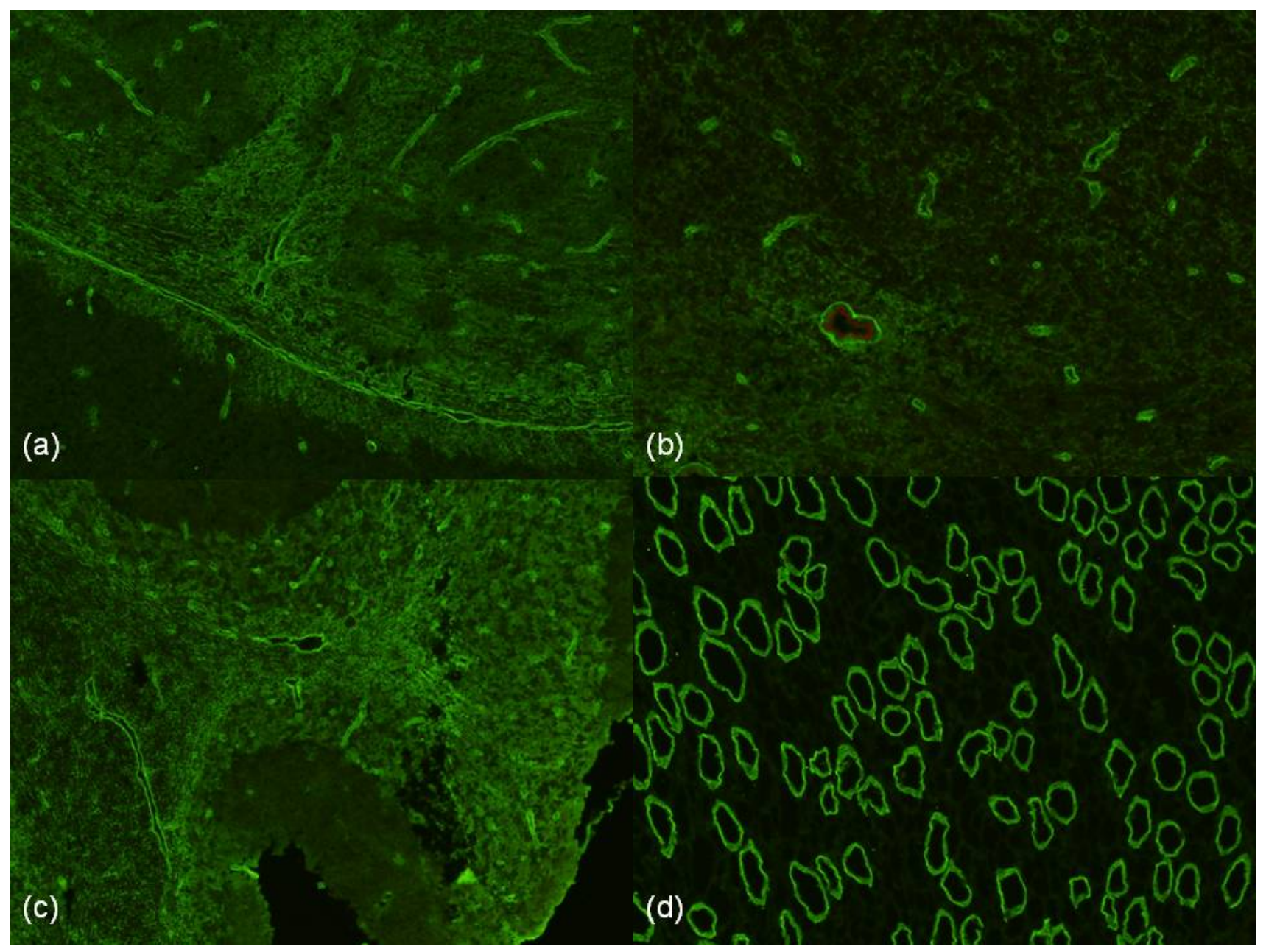




\subsection{Triggers for Autoimmunity}

A genetic predisposing factor is likely in $\mathrm{NMO}$, as the disease is relatively more prevalent in non-Caucasian populations, as compared to MS which is more common in Europeans [73-76]. However, the stand alone prevalence of NMO (not relative to MS) has not been systematically determined in any large population. Further clues favouring a genetic predisposition derive from familial NMO cases. While such cases have been described for many years [77], only a small proportion (3\%) of cases have a positive family history, predominantly those with Asian or Latino descent [78]. In the most comprehensive familial study to date (12 families, 25 affected individuals), the pattern of inheritance was thought to be complex [78]. The human leukocyte antigen (HLA) associations of NMO are contrasted with MS in Table 2. NMO IgG positivity has been found to be associated with HLA-DRB1*03 (DR3) in French (OR 3.08; 95\% CI 1.52-6.27, $p=0.001$ ) [79] and Brazilian (OR 3.23; 95\% CI 1.07-9.82, $p=0.04$ ) populations [80] and HLA-DPB1*0501 in Japanese (OR 4.8; 95\% CI 1.6-14.3, $p=0.032$ ) [81] and Chinese (OR 7.096; 95\% CI 2.011-25.044, $p=0.022$ ) populations [82]. Notably, these HLA haplotypes are also associated with other humoral autoimmune disorders such as systemic lupus erythematosus (SLE) [83] and Graves' disease [84]. Indeed, NMO often coexists with other autoimmune conditions such as SLE and Sjögren syndrome [23] and these disorders are also more common in family members of patients with NMO [78]. Recent diagnostic criteria for NMO have tended to exclude SLE and Sjögren syndrome as not being compatible with a diagnosis of NMO [13].

Table 2. Human leukocyte antigen (HLA) associations in NMO and MS.

\begin{tabular}{ccccccc}
\hline Disease & Population & N & DRB1 & DQA1 & DQB1 & DPB1 \\
\hline NMO & Japan [81] & 38 & & & & 0501 \\
& France [79] & 45 & 03 & - & 02 & \\
& Brazil [80] & 54 & 03 & & & \\
& USA [85] & 154 & (not 1501) & & & \\
& Han Chinese [82] & & & & & 0501 \\
& Martinque [86] & 42 & 03 & & - & \\
MS & Australia [87] & 100 & 1501 & 0102 & 0602 & - \\
\hline
\end{tabular}

Like many other autoimmune disorders NMO is also more common in women [10,88] suggesting that gender differences play a role in the pathogenesis of NMO. Genetic analysis of the $A Q P 4$ gene was carried out to determine if mutations in the gene are associated with NMO [89]. No significant association was found with the 8 selected SNPs. However, at position number 3180 in the $A Q P 4$ gene, which transcripts arginine at position 19, two missense mutations were observed in 3 out of 191 cases of NMO but not in any of 1363 controls. Whilst not statistically significant, it was speculated that loss of arginine 19 may impair palmitoylation of AQP4, which may increase the size of OAPs [49] and thereby generate immunogenic epitopes. Since Arginine 19 is in the regulatory sequence of M23 [90], this mutation could result in dysregulation of the transcription or translation of M23, resulting in a potentially immunogenic conformational change in OAPs. As described previously NMO IgG has high affinity for epitopes expressed in OAPs but lower affinity for isolated AQP4 protein [65]. 
In one series the onset of neurological symptoms in almost $30 \%$ of NMO cases was preceded by a viral or bacterial infection (more cases associated with varicella zoster and mycobacterium tuberculosis) [91] and vaccination against human papilloma virus has been reported to precede the onset of NMO in 4 teenage girls [92]. Parainfectious NMO may have a different immunopathogenesis as the majority of these cases have a monophasic course [91]. Rarely, a paraneoplastic association has also been described in NMO, especially with carcinoma of the breast and lung, and B cell-lymphoma [93]. A recent study of the T cells derived from the blood of $15 \mathrm{NMO}$ patients has supported molecular mimicry as a possible cause of autoimmunity in NMO. Homology between the immunogenic amino acids 66-75 of AQP4 and the surface protein ABC-TP of clostridia species especially Clostridium perfringens has been observed and ABC-TP was shown to cross react with anti-AQP4 T cells [94]. Clostridium perfringens is a ubiquitous organism and can occur in human gut as a commensal [95]. This study requires independent replication.

In MS, autoantibodies against myelin and other CNS antigens have been variably reported in as many as $60 \%-70 \%$ of cases [96] and the levels of autoantibodies fluctuate with relapses of disease [97]. However, no consistent high affinity serum autoantibody response is observed in MS and B-cells may be sensitised against self-antigens as an epiphenomenon during relapses. Similarly, there is a possibility that an initial disease process in the CNS of NMO patients attracts B-cells and sensitises them against AQP4. However, in an experiment to detect spontaneous production of NMO $\mathrm{IgG}$ in murine experimental autoimmune encephalomyelitis (EAE), extensive infiltration of immune cells into the CNS was seen without any detectable NMO IgG [98].

It remains to be discovered what, if any, role is played by molecular mimicry, bystander activation or a persistent infection in the initiation of autoantibody production in NMO.

\subsection{Is Anti-AQP4 Antibody Pathogenic?}

The antibody from the serum of NMO patients has been shown to exacerbate the clinical and pathological features of murine EAE $[66,99]$ and to cause disease when injected intracerebrally in wild-type mice [35]. However, NMO IgG is only pathogenic in the presence of human complement proteins $[35,100]$ or a pre-existing inflammatory state in the CNS such as occurs in EAE or mice pre-treated with Freund's complete adjuvant [101]. The stronger the pre-existing CNS inflammation, the more severe the disease. Therefore, in EAE models more extensive disease is induced by NMO $\operatorname{IgG}[66,99]$, whereas only mild disease is observed in mice pre-treated with Freund's complete adjuvant, which causes milder CNS inflammation than EAE [101]. AQP4 is expressed in non-CNS tissues [68,102], but no pathological involvement of extra neuronal tissues has been observed in NMO cases. This suggests that pathogenic potential of the autoantibody is restricted to the CNS. NMO IgG fails to produce disease in juvenile mice with incomplete BBB [66]; while access of NMO IgG to the CNS is a pre-requisite for the induction of disease, it is not sufficient to cause clinically relevant pathology in isolation. Higher titres of NMO IgG have been reported in patients with increased disease activity and severity $[68,103]$, consistent with antibody pathogenicity. However, antibody titres do not correlate closely with disease activity in all studies [60,104,105]. More questions have been raised about the pathogenicity of NMO IgG following a case report in which NMO IgG was detected in blood 10 years before the clinical onset of the disease [106] and in another case series where NMO IgG was 
detected in 2 patients with cancer but without any clinical manifestation of NMO [93]. It can be concluded that NMO IgG is pathogenic, but only in a specific CNS milieu.

\subsection{Immune Mediated Astrocytopathy}

NMO IgG binds with AQP4 and activates complement making the lytic complex C5b-9, which destroys astrocytes [107]. Neutrophils, natural killer cells, macrophages, tumour necrosis factor $\alpha$, interleukin (IL)-6, IL-1 $\beta$, and interferon-gamma have been shown to amplify this complement mediated damage [100]. Complement regulatory proteins (CRP) on astrocytes such as decay-accelerating factor (CD55), membrane cofactor protein (CD46), complement receptor 1 and protectin (CD59) may also be dysfunctional in NMO, thus facilitating complement mediated astrocyte injury. In mice injected intracerebrally with NMO IgG. NMO-like lesions are only produced when human, but not mouse, complement is co-administered [35]. It is known that murine CRP may not have a potent protective effect against heterologous complement [108,109]. CRP dysfunction secondary to autoantibodies has been reported in MS [110]. The possibility of dysfunctional CRP in NMO requires further investigation.

Anti-AQP4 antibody has been reported in some studies to cause internalisation of AQP4 [50,61,111]. However, internalisation of AQP4, a process that could paradoxically protect astrocytes from immune mediated cytotoxicity, is unlikely to be the principal pathogenic mechanism in NMO. As noted previously the absence of AQP4 function does not result in neurological disorder in AQP4 knockout mice [53]. Additionally, little or no internalisation of antibody-AQP4 complex is observed in primary astrocyte culture or in vivo, emphasising the limited applicability of AQP4-transfected cells when modelling human disease [52,112]. It has also been shown that astrocytes do not suffer any osmotic injury as NMO IgG does not disturb the function of AQP4 [113,114].

Perivascular glial fibrillary acid protein (GFAP) positive astrocytes are consistently lost in NMO lesions in contrast with MS [36,37], where lesional GFAP is usually upregulated [115]. CSF levels of GFAP are markedly elevated during relapses of NMO but not MS [116]. GFAP is a cytoskeletal protein that plays a role in astrocyte motility and structure [115]. It is highly expressed by reactive astrocytes [117].

\subsection{Immunopathogenesis}

Systemic production of autoantibody with disease limited to the CNS implicates the presence of orchestrating $\mathrm{T}$ helper cells as well as a cascade of cytokines in the periphery and within the CNS. B cells are also attracted to the CNS by chemokines secreted at sites of inflammation. A study involving 31 NMO patients found various Th2 related cytokines such as IL-1 receptor antagonist, IL-5, IL-10 and IL-13; and the Th17 related cytokines IL-6, IL-8 and granulocyte colony stimulating factor to be elevated in the CSF. However, the signature Th2 cytokine, IL-4, and Th17 cytokine, IL-17, were not detected in the CSF [118]. Other studies have shown increased levels of IL-17 in the CSF of NMO patients $[119,120]$. Therefore, Th17 cells may have an intermittent role in the CNS inflammation that characterises NMO. Chitinases, hydrolases secreted by the innate immune cells that play a role in Th2 as well as Th1 related inflammatory processes, are also increased in the CSF of NMO patients. In response to IL-13 monocytes obtained from NMO patients secrete chitinases that increase in vitro 
chemotaxis of eosinophils, macrophages and $\mathrm{T}$ cells across the BBB by promoting the secretion of various cytokines IL-8, RANTES (CCL5), MCP1 (CCL2), and eotaxins by monocytes [121]. Eosinophils and macrophages are abundant in NMO lesions [122]. CSF levels of CXCL13, a potent chemo-attractant for B cells, are elevated and correlate with disease severity [123]. As indicated previously, anti-AQP4 B cells have been detected in the CSF of NMO patients [71]. CXCL13 is secreted by sensitised T helper cells [124] and antigen presenting cells (APC) [125]. B-cell activating factor (BAFF) is increased in the CSF but not serum of NMO patients [126]. BAFF, secreted by innate immune cells, APC [127] and activated astrocytes [128], increases the survival and maturation of B cells through NF- $\kappa B$ [129]. Thus, BAFF can perpetuate the auto-reactive B cell population in the CNS. It is interesting to note that treatment with both $\beta$-interferon and glatiramer acetate was found to increase levels of BAFF in the serum of MS patients [126]. This may account for the apparent worsening of NMO with $\beta$-interferon [28-30]. Despite similar changes in BAFF occurring with glatiramer acetate the same concerns regarding its use in NMO have not been raised [130,131].

IL-6 is elevated not only in the CSF but also in the serum of patients with NMO [118,132], particularly in patients with more severe disease [132]. This proinflammatory cytokine, which can also be secreted by activated astrocytes [133], increases the survival of NMO IgG producing B cells and the production of antibody [72]. In ex vivo experiments in murine spinal cord, IL-6 increased the induced NMO-like lesions [100]. In a study of 18 NMO patients, IL-9, a T cell growth factor, was elevated in the serum [134] but, not the CSF [118]. IL-6 is involved in the development of IL-17-secreting CD4 ${ }^{+} \mathrm{T}$ cells (Th17) [135]. Th17 cells have been implicated in many autoimmune disorders such as rheumatoid arthritis, psoriasis, MS and inflammatory bowel disease [136]. Th17 cells and their principal product, IL-17, are found to be increased in serum from patients with NMO [137,138], and some studies as seen above have also shown elevated IL-17 in the CSF [119,120], suggesting the involvement of Th17 cells and IL-17 in the pathogenesis of the disease. IL-17 is seen to mediate inflammation in the brain of EAE mice by promoting microglial activation [139]. Th17 cells may dictate the autoimmune milieu that facilitates the pathogenesis of NMO. A subset of B cells $\left(\mathrm{CD} 27{ }^{\text {high }} \mathrm{CD} 38^{\text {high }} \mathrm{CD} 180^{-}\right.$with low $\mathrm{CD} 20$ and $\mathrm{CD}^{-} 9^{-}$), which may be producing anti-AQP4 antibody, appear to be activated [72]. Further implicating a role for humoral immunity in $\mathrm{NMO}, \mathrm{CD} 27^{+}$memory B cell levels rise in association with relapses [34]. There is some evidence that cellular autoimmunity is also initiated as $\mathrm{CD}^{+} \mathrm{T}$ cells against AQP4 are detectable in the blood of patients with NMO [140,141].

Rituximab has been found to be clinically effective in NMO [33,34] and reduces the levels of anti-NMO IgG, but the antibody does not completely disappear [34,103,142]. There may also be a BAFF related transient elevation in the anti-NMO titres observed 2 weeks after the first injection of rituximab [142]. One possible explanation for this is that plasma cells, which do not express CD20 (the target of rituximab), may continue to produce antibody for a period of time, possibly at an increased rate due to the depletion of memory B cells and other modulatory Bcells (regulatory B cells) which do carry CD20 [143]. Repeated rituximab therapy may reduce the level of NMO IgG after the depletion of memory B cells and natural death of short-lived plasmablasts/plasma cells. Long-lived plasma cells may continue to secrete autoantibody despite the treatment with rituximab [144]. An alternative explanation is that it is purely through the modulatory effects of B cells on $\mathrm{T}$ cells that rituximab is having an effect, such that removal of memory B cells and activated B cells diminishes the proinflammatory milieu. 
Disruption of the BBB is required for NMO IgG to enter the CNS. Serum from NMO patients can cause breakdown of the BBB $[145,146]$ by an unknown mechanism. However, autoantibodies against cultured human brain microvascular endothelial cells were detected in 10 out of 14 seropositive NMO patients. These autoantibodies, which are distinct from anti-AQP4, were observed to reduce the expression of the tight junction proteins, that constitute the BBB, possibly through the autocrine secretion of vascular endothelial growth factor [146]. The BBB is further disrupted by injury to astrocytic foot processes sustained in the disease process [111].

Figure 2. Schematic diagram of the immunopathogenesis of NMO. APC: antigen presenting cell; B prec: precursor B cell; Plasm: Plasma cell; Mem B: memory B cell; Mem Th17: memory Th17 cell; Neut: neutrophil; BBB: blood brain barrier; CDC: complement dependant cytotoxicity; CDCC: complement dependant cell mediated cytotoxicity; Astr: astrocyte; Olig: oligodendrocyte; Macro: macrophage; Eos: eosinophil.

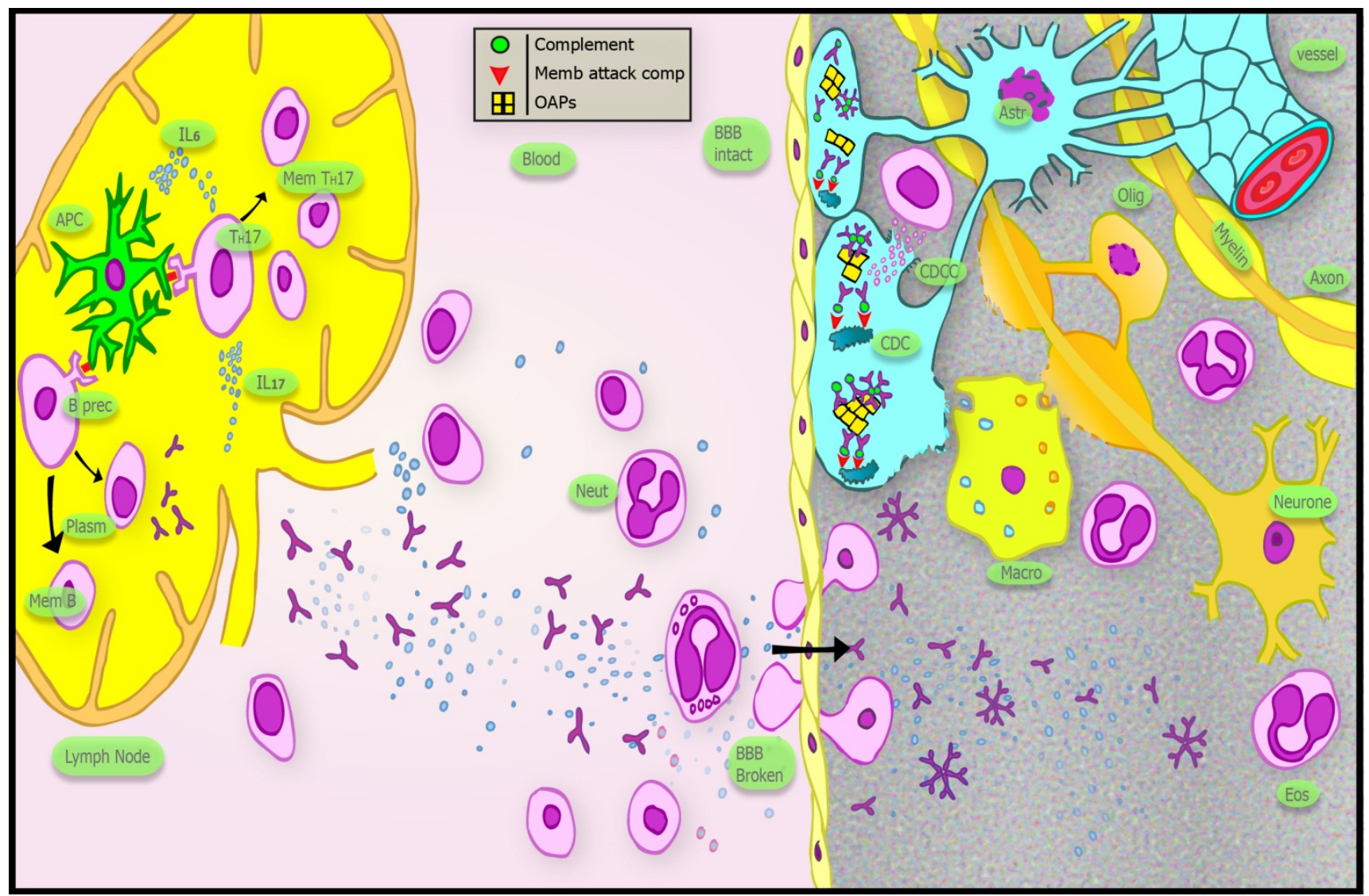

Oligodendrocyte damage appears to follow immune mediated astrocyte injury [36,101] and these cells are not affected in AQP4 null mice when exposed to NMO IgG and complement factors [100]. Glutamate induced excitotoxicity is one potential mechanism of oligodendrocyte injury. Glutamate is removed by excitatory amino acid transporter 2 (EAAT2) present on astrocytes in association with AQP4. In AQP4 transfected cells, the glutamate transporter is internalised with antibody-AQP4 complex, implicating glutamate excitotoxicity in NMO [50,51]. However, studies utilising primary astrocyte cultures as a substrate and in vivo studies have failed to demonstrate significant AQP4 complex or glutamate transporter internalisation [52,112]. Recent work has suggested that NMO IgG bound to the M23 isoform of AQP4 increases resistance to internalisation but does cause 
internalisation of the M1 isoform [112]. AQP4 has been observed in autopsy studies to be lost both in MS and NMO lesions [37,147]. This may be due to loss of astrocytes rather than internalisation. Loss of AQP4 in EAE models has been observed to be neuroprotective [98], but it is likely that this effect is mediated by its water channelling action, which is not affected by NMO IgG binding [113,114]. Thus, loss of AQP4 in NMO, either by internalisation or astrocyte loss, is one of the markers of the disease but may not be a primary pathogenic process. Whilst it is possible that the inflammatory process primarily targeting astrocytes causes bystander injury to nearby oligodendrocytes, widespread loss of oligodendrocytes is reported in early NMO lesions in the absence of a significant macrophage infiltrate [36]. The immunoglobulin predominantly seen in lesions of NMO patients in one study was of IgM type [148] but as noted earlier it is only detected in the blood of $10 \%$ of patients [62]. A possible explanation for this is intrathecal synthesis by local B-cells undergoing class switching. However, another study also showed IgG along with IgM in lesions of NMO patients thus supporting the role of IgG as a pathogenic antibody [36]. The immunopathogenesis of NMO is summarised in Figure 2.

\subsection{Histopathology of $N M O$}

The earliest pathological descriptions of NMO highlighted the frequent occurrence of necrosis with cavitation, hyalinisation of small vessels and perivascular inflammatory infiltrates. These features were helpful in distinguishing NMO from MS. More recent work has indicated the importance of perivascular deposition of immunoglobulin and complement [148] and its localisation to the vascular glial limiting membrane [149]. The infiltrate consists of macrophages, granulocytes and eosinophils with a general paucity of lymphocytes [122]. Modern histopathological techniques have demonstrated the specificity of acute fragmentation and loss of perivascular GFAP-positive astrocyte foot processes and their cell bodies as an early and consistent feature of NMO [36,150]. Whilst loss of AQP4 is seen in NMO lesions [37,147], this is not consistent and is also seen in MS [151,152]. Relative preservation of myelin in early lesions with massive astrocyte destruction implicates astrocyte injury as the primary pathological event in NMO [37,147]. The presence of myelin loss and phagocytosis by macrophages in subacute NMO lesions suggests that this is a secondary phenomenon. Morphologically distinct unipolar and bipolar GFAP-positive astrocytes are seen in demyelinated subacute lesions suggesting that astrocyte progenitor cells may be responsible for reparative processes in NMO [37,147,153]. Interestingly, significant necrosis of axons was not seen in early and subacute lesions [36]. Intramyelenic oedema with partial astrocyte preservation may be responsible for the presumed vasogenic oedema seen on MRI as extensive white matter lesions in the brain [112]. The typical histopathological appearances in NMO are illustrated in Figure 3. 
Figure 3. Serial sections from a biopsy of an early brain white matter NMO lesion immunostained for (a) C3d and (b) GFAP. (a) Typical perivascular complement deposition around numerous small vessels; (b) Particulate GFAP-positive debris with a perivascular accentuation indicating massive astrocyte destruction in a region with relatively preserved myelin architecture. Note that no normal astrocytes are visible.
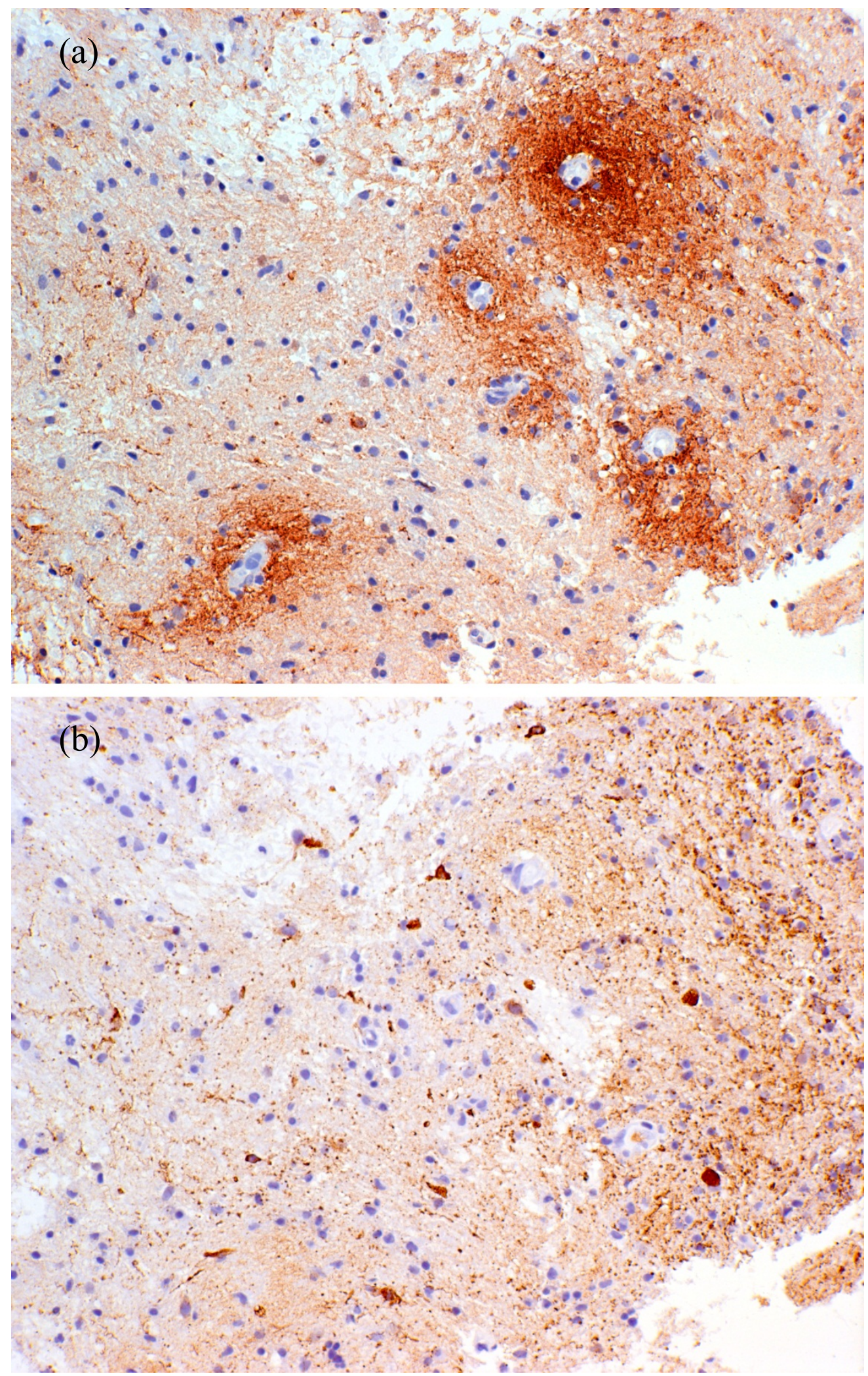


\section{Conclusions}

Great strides have been made in elucidating the molecular underpinnings of NMO, but aspects of the pathogenesis remain unknown and no currently proposed disease model is completely satisfactory.

It seems likely that NMO is an autoimmune disease that develops in genetically susceptible individuals. There is already some evidence for specific HLA alleles and polymorphisms of the AQP4 gene being associated with NMO. Infection, vaccination, and neoplasm may trigger the disease process in some cases but a recognisable initiating event is lacking in most. In the schema presented in Figure 2, this trigger induces the release of inflammatory cytokines, including IL-6, and Th17 cells are stimulated. A subset of B-cells in the peripheral tissues is stimulated to produce anti-AQP4 IgG antibody. The BBB is made permeable to the autoantibody by either a systemic inflammatory response or a local pathological process in the CNS. Auto-reactive B cells may also enter the CNS and undergo class switching to produce IgM autoantibody. The antibody fixes complement on AQP4 expressing astrocytic foot processes. Stellate astrocytes are damaged by complement dependent cytotoxicity and complement dependent cellular cytotoxicity. Oligodendrocytes that are in close proximity to astrocyte foot processes are possibly affected through bystander inflammatory damage or, more likely, loss of trophic support from astrocytes. The resulting demyelination causes loss of saltatory conduction and conduction block, leading to neurological deficit. With continuing or repeated inflammation, substantial neuro-axonal loss ensues. The near absence of progressive forms of NMO (primary or secondary) suggests that neuro-axonal damage is the result of the acute inflammation, whether directly or indirectly, rather than as a result of a secondary degenerative process as appears to be the case in some forms of MS.

Some CNS sites, such as cerebellum, express $A Q P 4$ abundantly but are not usually involved in NMO. Similarly, cerebral cortex expresses $A Q P 4$ but is not affected. This may be due to the specific local immune environment. Elucidation of such protective mechanisms will be helpful in identifying new therapeutic targets. The processes responsible for oligodendrocyte loss are also largely unknown and the mechanism of axonal injury in chronic lesions is also poorly understood. Important questions regarding the aetiopathogenesis of seronegative cases with NMO phenotypes remain. Do these cases have a different antigenic target (heterogeneity) or do they represent a milder form of the disease (forme fruste), or do they reflect technical problems with the currently available NMO IgG assays (false negatives)?

As the first autoimmune disease of the CNS for which a specific autoantibody and antigenic target have been identified NMO represents a significant opportunity to better understand and hopefully treat its more heterogeneous and complex cousin, MS. Very recent research has highlighted a novel potential therapeutic approach utilising small-molecule inhibitors to reduce AQP4 mediated astrocyte cytotoxicity by disrupting the interaction between NMO-IgG and M23-AQP4 [154]. These experiments demonstrate the very direct way in which a greater understanding of the pathogenesis of autoimmune diseases such as NMO can lead to new therapeutic interventions. The prominent role played by IL-6 in NMO has led to the suggestion that IL-6 receptor blockade may be an effective therapy [72]. The development of fully humanised monoclonal antibodies against the B-cell antigens CD20 [155] and CD19 [156] raise exciting prospects for improved tolerability and potentially greater efficacy in the treatment of NMO. 


\section{Acknowledgements}

We are grateful to Jacob Sharples and Robert Loudon for assistance with the illustration. Wajih Bukhari is supported by a Fellowship Scholarship from Multiple Sclerosis Research Australia.

\section{References}

1. Allbutt, T. On the opthalmoscopic signs of spinal disease. Lancet 1870, 1, 76-78.

2. Erb, W. About the concurrence of optic neuritis and subacute myelitis. Arch. Psychiatr. Nervenkr. 1879, 1, 146-157.

3. Jarius, S.; Wildemann, B. On the contribution of thomas clifford allbutt, F.R.S., to the early history of neuromyelitis optica. J. Neurol. 2012, doi:10.1007/s00415-012-6594-3.

4. Devic, E. Myélite subaiguë compliquée de névrite optique. Bull. Med. (Paris) 1894, 8, 1033-1034.

5. Totsuka, S. Clinico-pathological studies on the two cases of neuromyelitis optica (Devic's disease) with a chronic clinical course, with especial reference on its relationship to multiple sclerosis. Folia Psychiatr. Neurol. Jpn. 1962, 64, 1149-1165.

6. Wingerchuk, D.M.; Hogancamp, W.F.; O’Brien, P.C.; Weinshenker, B.G. The clinical course of neuromyelitis optica (Devic's syndrome). Neurology 1999, 53, 1107-1114.

7. Lennon, V.A.; Wingerchuk, D.M.; Kryzer, T.J.; Pittock, S.J.; Lucchinetti, C.F.; Fujihara, K.; Nakashima, I.; Weinshenker, B.G. A serum autoantibody marker of neuromyelitis optica: Distinction from multiple sclerosis. Lancet 2004, 364, 2106-2112.

8. Kim, J.S.; Park, Y.H.; Kim, S.M.; Kim, S.H.; Park, K.S.; Sung, J.J.; Lee, K.W. A case of chronic progressive myelopathy. Mult. Scler. 2010, 16, 1255-1257.

9. Wingerchuk, D.M.; Pittock, S.J.; Lucchinetti, C.F.; Lennon, V.A.; Weinshenker, B.G. A secondary progressive clinical course is uncommon in neuromyelitis optica. Neurology 2007, 68, 603-605.

10. Jarius, S.; Ruprecht, K.; Wildemann, B.; Kuempfel, T.; Ringelstein, M.; Geis, C.; Kleiter, I.; Kleinschnitz, C.; Berthele, A.; Brettschneider, J.; et al. Contrasting disease patterns in seropositive and seronegative neuromyelitis optica: A multicentre study of 175 patients. J. Neuroinflamm. 2012, 9, 14.

11. Jarius, S.; Paul, F.; Franciotta, D.; Ruprecht, K.; Ringelstein, M.; Bergamaschi, R.; Rommer, P.; Kleiter, I.; Stich, O.; Reuss, R.; et al. Cerebrospinal fluid findings in aquaporin-4 antibody positive neuromyelitis optica: Results from 211 lumbar punctures. J. Neurol. Sci. 2011, 306, 82-90.

12. Pittock, S.J.; Lennon, V.A.; Krecke, K.; Wingerchuk, D.M.; Lucchinetti, C.F.; Weinshenker, B.G. Brain abnormalities in neuromyelitis optica. Arch. Neurol. 2006, 63, 390-396.

13. Wingerchuk, D.M.; Lennon, V.A.; Pittock, S.J.; Lucchinetti, C.F.; Weinshenker, B.G. Revised diagnostic criteria for neuromyelitis optica. Neurology 2006, 66, 1485-1489.

14. Wingerchuk, D.M.; Lennon, V.A.; Lucchinetti, C.F.; Pittock, S.J.; Weinshenker, B.G. The spectrum of neuromyelitis optica. Lancet Neurol. 2007, 6, 805-815.

15. Bizzoco, E.; Lolli, F.; Repice, A.M.; Hakiki, B.; Falcini, M.; Barilaro, A.; Taiuti, R.; Siracusa, G.; Amato, M.P.; Biagioli, T.; et al. Prevalence of neuromyelitis optica spectrum disorder and phenotype distribution. J. Neurol. 2009, 256, 1891-1898. 
16. McKeon, A.; Lennon, V.A.; Lotze, T.; Tenenbaum, S.; Ness, J.M.; Rensel, M.; Kuntz, N.L.; Fryer, J.P.; Homburger, H.; Hunter, J.; et al. CNS aquaporin-4 autoimmunity in children. Neurology 2008, 71, 93-100.

17. Takahashi, T.; Miyazawa, I.; Misu, T.; Takano, R.; Nakashima, I.; Fujihara, K.; Tobita, M.; Itoyama, Y. Intractable hiccup and nausea in neuromyelitis optica with anti-aquaporin-4 antibody: A herald of acute exacerbations. J. Neurol. Neurosurg. Psychiatry 2008, 79, 1075-1078.

18. Pittock, S.J.; Weinshenker, B.G.; Lucchinetti, C.F.; Wingerchuk, D.M.; Corboy, J.R.; Lennon, V.A. Neuromyelitis optica brain lesions localized at sites of high aquaporin 4 expression. Arch. Neurol. 2006, 63, 964-968.

19. Makino, T.; Ito, S.; Mori, M.; Yonezu, T.; Ogawa, Y.; Kuwabara, S. Diffuse and heterogeneous T2-hyperintense lesions in the splenium are characteristic of neuromyelitis optica. Mult. Scler. 2012, doi:10.1177/1352458512454772.

20. Ikeda, K.; Ito, H.; Hidaka, T.; Takazawa, T.; Sekine, T.; Yoshii, Y.; Hirayama, T.; Kawabe, K.; Kano, O.; Iwasaki, Y. Repeated non-enhancing tumefactive lesions in a patient with a neuromyelitis optica spectrum disorder. Intern. Med. 2011, 50, 1061-1064.

21. Newey, C.R.; Bermel, R.A. Fulminant cerebral demyelination in neuromyelitis optica. Neurology 2011, 77, 193.

22. Orton, S.M.; Herrera, B.M.; Yee, I.M.; Valdar, W.; Ramagopalan, S.V.; Sadovnick, A.D.; Ebers, G.C.; Canadian Collaborative Study, G. Sex ratio of multiple sclerosis in canada: A longitudinal study. Lancet Neurol. 2006, 5, 932-936.

23. Wingerchuk, D.M.; Weinshenker, B.G. The emerging relationship between neuromyelitis optica and systemic rheumatologic autoimmune disease. Mult. Scler. 2012, 18, 5-10.

24. Wynn, D.R.; Rodriguez, M.; O'Fallon, W.M.; Kurland, L.T. A reappraisal of the epidemiology of multiple sclerosis in Olmsted county, Minnesota. Neurology 1990, 40, 780-786.

25. Broadley, S.A.; Deans, J.; Sawcer, S.J.; Clayton, D.; Compston, D.A. Autoimmune disease in first-degree relatives of patients with multiple sclerosis. A UK survey. Brain 2000, 123, $1102-1111$.

26. Spadaro, M.; Amendolea, M.A.; Mazzucconi, M.G.; Fantozzi, R.; Di Lello, R.; Zangari, P.; Masala, G. Autoimmunity in multiple sclerosis: Study of a wide spectrum of autoantibodies. Mult. Scler. 1999, 5, 121-125.

27. Henderson, R.D.; Bain, C.J.; Pender, M.P. The occurrence of autoimmune diseases in patients with multiple sclerosis and their families. J. Clin. Neurosci. 2000, 7, 434-437.

28. Kim, S.H.; Kim, W.; Li, X.F.; Jung, I.J.; Kim, H.J. Does interferon $\beta$ treatment exacerbate neuromyelitis optica spectrum disorder? Mult. Scler. 2012, doi:10.1177/1352458512439439.

29. Shimizu, J.; Hatanaka, Y.; Hasegawa, M.; Iwata, A.; Sugimoto, I.; Date, H.; Goto, J.; Shimizu, T.; Takatsu, M.; Sakurai, Y.; et al. IFNbeta-1b may severely exacerbate Japanese optic-spinal MS in neuromyelitis optica spectrum. Neurology 2010, 75, 1423-1427.

30. Palace, J.; Leite, M.I.; Nairne, A.; Vincent, A. Interferon beta treatment in neuromyelitis optica: Increase in relapses and aquaporin 4 antibody titers. Arch. Neurol. 2010, 67, 1016-1017.

31. Watanabe, S.; Nakashima, I.; Misu, T.; Miyazawa, I.; Shiga, Y.; Fujihara, K.; Itoyama, Y. Therapeutic efficacy of plasma exchange in NMO-IgG-positive patients with neuromyelitis optica. Mult. Scler. 2007, 13, 128-132. 
32. Papeix, C.; Vidal, J.S.; de Seze, J.; Pierrot-Deseilligny, C.; Tourbah, A.; Stankoff, B.; Lebrun, C.; Moreau, T.; Vermersch, P.; Fontaine, B.; et al. Immunosuppressive therapy is more effective than interferon in neuromyelitis optica. Mult. Scler. 2007, 13, 256-259.

33. Jacob, A.; Weinshenker, B.G.; Violich, I.; McLinskey, N.; Krupp, L.; Fox, R.J.; Wingerchuk, D.M.; Boggild, M.; Constantinescu, C.S.; Miller, A.; et al. Treatment of neuromyelitis optica with rituximab: Retrospective analysis of 25 patients. Arch. Neurol. 2008, 65, 1443-1448.

34. Kim, S.H.; Kim, W.; Li, X.F.; Jung, I.J.; Kim, H.J. Repeated treatment with rituximab based on the assessment of peripheral circulating memory B cells in patients with relapsing neuromyelitis optica over 2 years. Arch. Neurol. 2011, 68, 1412-1420.

35. Saadoun, S.; Waters, P.; Bell, B.A.; Vincent, A.; Verkman, A.S.; Papadopoulos, M.C. Intra-cerebral injection of neuromyelitis optica immunoglobulin $\mathrm{G}$ and human complement produces neuromyelitis optica lesions in mice. Brain 2010, 133, 349-361.

36. Parratt, J.D.; Prineas, J.W. Neuromyelitis optica: A demyelinating disease characterized by acute destruction and regeneration of perivascular astrocytes. Mult. Scler. 2010, 16, 1156-1172.

37. Misu, T.; Fujihara, K.; Kakita, A.; Konno, H.; Nakamura, M.; Watanabe, S.; Takahashi, T.; Nakashima, I.; Takahashi, H.; Itoyama, Y. Loss of aquaporin 4 in lesions of neuromyelitis optica: Distinction from multiple sclerosis. Brain 2007, 130, 1224-1234.

38. Preston, G.M.; Carroll, T.P.; Guggino, W.B.; Agre, P. Appearance of water channels in xenopus oocytes expressing red cell CHIP28 protein. Science 1992, 256, 385-387.

39. Verkman, A.S. More than just water channels: Unexpected cellular roles of aquaporins. J. Cell Sci. 2005, 118, 3225-3232.

40. Nielsen, S.; Nagelhus, E.A.; Amiry-Moghaddam, M.; Bourque, C.; Agre, P.; Ottersen, O.P. Specialized membrane domains for water transport in glial cells: High-resolution immunogold cytochemistry of aquaporin-4 in rat brain. J. Neurosci. 1997, 17, 171-180.

41. Frigeri, A.; Gropper, M.A.; Umenishi, F.; Kawashima, M.; Brown, D.; Verkman, A.S. Localization of MIWC and GLIP water channel homologs in neuromuscular, epithelial and glandular tissues. J. Cell Sci. 1995, 108, 2993-3002.

42. Li, J.; Patil, R.V.; Verkman, A.S. Mildly abnormal retinal function in transgenic mice without muller cell aquaporin-4 water channels. Invest. Ophth. Vis. Sci. 2002, 43, 573-579.

43. Venero, J.L.; Vizuete, M.L.; Ilundain, A.A.; Machado, A.; Echevarria, M.; Cano, J. Detailed localization of aquaporin-4 messenger RNA in the CNS: Preferential expression in periventricular organs. Neuroscience 1999, 94, 239-250.

44. Agre, P.; King, L.S.; Yasui, M.; Guggino, W.B.; Ottersen, O.P.; Fujiyoshi, Y.; Engel, A.; Nielsen, S. Aquaporin water channels-From atomic structure to clinical medicine. J. Physiol. 2002, 542, 3-16.

45. Lu, M.Q.; Lee, M.D.; Smith, B.L.; Jung, J.S.; Agre, P.; Verdijk, M.A.J.; Merkx, G.; Rijs, J.P.L.; Deen, P.M.T. The human AQP4 gene: Definition of the locus encoding two water channel polypeptides in brain. Proc. Natl. Acad. Sci. USA 1996, 93, 10908-10912.

46. Neely, J.D.; Christensen, B.M.; Nielsen, S.; Agre, P. Heterotetrameric composition of aquaporin-4 water channels. Biochemistry 1999, 38, 11156-11163. 
47. Furman, C.S.; Gorelick-Feldman, D.A.; Davidson, K.G.; Yasumura, T.; Neely, J.D.; Agre, P.; Rash, J.E. Aquaporin-4 square array assembly: Opposing actions of M1 and M23 isoforms. Proc. Natl. Acad. Sci. USA 2003, 100, 13609-13614.

48. Strand, L.; Moe, S.E.; Solbu, T.T.; Vaadal, M.; Holen, T. Roles of aquaporin-4 isoforms and amino acids in square array assembly. Biochemistry 2009, 48, 5785-5793.

49. Suzuki, H.; Nishikawa, K.; Hiroaki, Y.; Fujiyoshi, Y. Formation of aquaporin-4 arrays is inhibited by palmitoylation of $N$-terminal cysteine residues. BBA-Biomembranes 2008, 1778, 1181-1189.

50. Hinson, S.R.; Roemer, S.F.; Lucchinetti, C.F.; Fryer, J.P.; Kryzer, T.J.; Chamberlain, J.L.; Howe, C.L.; Pittock, S.J.; Lennon, V.A. Aquaporin-4-binding autoantibodies in patients with neuromyelitis optica impair glutamate transport by down-regulating EAAT2. J. Exp. Med. 2008, 205, 2473-2481.

51. Marignier, R.; Nicolle, A.; Watrin, C.; Touret, M.; Cavagna, S.; Varrin-Doyer, M.; Cavillon, G.; Rogemond, V.; Confavreux, C.; Honnorat, J.; et al. Oligodendrocytes are damaged by neuromyelitis optica immunoglobulin G via astrocyte injury. Brain 2010, 133, 2578-2591.

52. Ratelade, J.; Bennett, J.L.; Verkman, A.S. Evidence against cellular internalization in vivo of NMO-IgG, aquaporin-4, and excitatory amino acid transporter 2 in neuromyelitis optica. J. Biol. Chem. 2011, 286, 45156-45164.

53. Manley, G.T.; Fujimura, M.; Ma, T.; Noshita, N.; Filiz, F.; Bollen, A.W.; Chan, P.; Verkman, A.S. Aquaporin-4 deletion in mice reduces brain edema after acute water intoxication and ischemic stroke. Nat. Med. 2000, 6, 159-163.

54. Saadoun, S.; Papadopoulos, M.C.; Watanabe, H.; Yan, D.; Manley, G.T.; Verkman, A.S. Involvement of aquaporin-4 in astroglial cell migration and glial scar formation. J. Cell Sci. 2005, 118, 5691-5698.

55. Papadopoulos, M.C.; Manley, G.T.; Krishna, S.; Verkman, A.S. Aquaporin-4 facilitates reabsorption of excess fluid in vasogenic brain edema. FASEB J. 2004, 18, 1291-1293.

56. Bloch, O.; Papadopoulos, M.C.; Manley, G.T.; Verkman, A.S. Aquaporin-4 gene deletion in mice increases focal edema associated with staphylococcal brain abscess. J. Neurochem. 2005, 95, 254-262.

57. Waters, P.; Leite, M.I.; Gray, B.; Vincent, A.; Jiang, Y.; Palace, J. Aquaporin-4 M23 isoform provides a more sensitive assay for aquaporin-4 antibodies. J. Neurol. Neurosurg. Psychiatry 2010, 81, E32.

58. Ketelslegers, I.A.; Modderman, P.W.; Vennegoor, A.; Killestein, J.; Hamann, D.; Hintzen, R.Q. Antibodies against aquaporin-4 in neuromyelitis optica: Distinction between recurrent and monophasic patients. Mult. Scler. 2011, 17, 1527-1530.

59. Jarius, S.; Wildemann, B. AQP4 antibodies in neuromyelitis optica: Diagnostic and pathogenetic relevance. Nat. Rev. Neurol. 2010, 6, 383-392.

60. Kira, J. Autoimmunity in neuromyelitis optica and opticospinal multiple sclerosis: Astrocytopathy as a common denominator in demyelinating disorders. J. Neurol. Sci. 2011, 311, 69-77.

61. Hinson, S.R.; Pittock, S.J.; Lucchinetti, C.F.; Roemer, S.F.; Fryer, J.P.; Kryzer, T.J.; Lennon, V.A. Pathogenic potential of IgG binding to water channel extracellular domain in neuromyelitis optica. Neurology 2007, 69, 2221-2231. 
62. Jarius, S.; Franciotta, D.; Bergamaschi, R.; Wildemann, B.; Wandinger, K.P. Immunoglobulin M antibodies to aquaporin-4 in neuromyelitis optica and related disorders. Clin. Chem. Lab. Med. 2010, 48, 659-663.

63. Tani, T.; Sakimura, K.; Tsujita, M.; Nakada, T.; Tanaka, M.; Nishizawa, M.; Tanaka, K. Identification of binding sites for anti-aquaporin 4 antibodies in patients with neuromyelitis optica. J. Neuroimmunol. 2009, 211, 110-113.

64. Crane, J.M.; Lam, C.; Rossi, A.; Gupta, T.; Bennett, J.L.; Verkman, A.S. Binding affinity and specificity of neuromyelitis optica autoantibodies to aquaporin-4 M1/M23 isoforms and orthogonal arrays. J. Biol. Chem. 2011, 286, 16516-16524.

65. Nicchia, G.P.; Mastrototaro, M.; Rossi, A.; Pisani, F.; Tortorella, C.; Ruggieri, M.; Lia, A.; Trojano, M.; Frigeri, A.; Svelto, M. Aquaporin-4 orthogonal arrays of particles are the target for neuromyelitis optica autoantibodies. Glia 2009, 57, 1363-1373.

66. Bradl, M.; Misu, T.; Takahashi, T.; Watanabe, M.; Mader, S.; Reindl, M.; Adzemovic, M.; Bauer, J.; Berger, T.; Fujihara, K.; et al. Neuromyelitis optica: Pathogenicity of patient immunoglobulin in vivo. Ann. Neurol. 2009, 66, 630-643.

67. Ratelade, J.; Bennett, J.L.; Verkman, A.S. Intravenous neuromyelitis optica autoantibody in mice targets aquaporin-4 in peripheral organs and area postrema. PLoS One 2011, 6, e27412.

68. Takahashi, T.; Fujihara, K.; Nakashima, I.; Misu, T.; Miyazawa, I.; Nakamura, M.; Watanabe, S.; Shiga, Y.; Kanaoka, C.; Fujimori, J.; et al. Anti-aquaporin-4 antibody is involved in the pathogenesis of NMO: A study on antibody titre. Brain 2007, 130, 1235-1243.

69. Kalluri, S.R.; Illes, Z.; Srivastava, R.; Cree, B.; Menge, T.; Bennett, J.L.; Berthele, A.; Hemmer, B. Quantification and functional characterization of antibodies to native aquaporin 4 in neuromyelitis optica. Arch. Neurol. 2010, 67, 1201-1208.

70. Klawiter, E.C.; Alvarez, E., 3rd; Xu, J.; Paciorkowski, A.R.; Zhu, L.; Parks, B.J.; Cross, A.H.; Naismith, R.T. NMO-IgG detected in CSF in seronegative neuromyelitis optica. Neurology 2009, 72, 1101-1103.

71. Bennett, J.L.; Lam, C.; Kalluri, S.R.; Saikali, P.; Bautista, K.; Dupree, C.; Glogowska, M.; Case, D.; Antel, J.P.; Owens, G.P.; et al. Intrathecal pathogenic anti-aquaporin-4 antibodies in early neuromyelitis optica. Ann. Neurol. 2009, 66, 617-629.

72. Chihara, N.; Aranami, T.; Sato, W.; Miyazaki, Y.; Miyake, S.; Okamoto, T.; Ogawa, M.; Toda, T.; Yamamura, T. Interleukin 6 signaling promotes anti-aquaporin 4 autoantibody production from plasmablasts in neuromyelitis optica. Proc. Natl. Acad. Sci. USA 2011, 108, 3701-3706.

73. Kira, J. Multiple sclerosis in the japanese population. Lancet Neurol. 2003, 2, 117-127.

74. Osuntokun, B.O. The pattern of neurological illness in tropical Africa. Experience at Ibadan, Nigeria. J. Neurol. Sci. 1971, 12, 417-442.

75. Chopra, J.S.; Radhakrishnan, K.; Sawhney, B.B.; Pal, S.R.; Banerjee, A.K. Multiple sclerosis in north-west India. Acta Neurol. Scand. 1980, 62, 312-321.

76. Papais-Alvarenga, R.M.; Miranda-Santos, C.M.; Puccioni-Sohler, M.; de Almeida, A.M.; Oliveira, S.; Basilio De Oliveira, C.A.; Alvarenga, H.; Poser, C.M. Optic neuromyelitis syndrome in Brazilian patients. J. Neurol. Neurosurg. Psychiatry 2002, 73, 429-435.

77. McAlpine, D. Familial neuromyelitis optica: Its occurrence in identical twins. Brain 1938, 61, 430-448. 
78. Matiello, M.; Kim, H.J.; Kim, W.; Brum, D.G.; Barreira, A.A.; Kingsbury, D.J.; Plant, G.T.; Adoni, T.; Weinshenker, B.G. Familial neuromyelitis optica. Neurology 2010, 75, 310-315.

79. Zephir, H.; Fajardy, I.; Outteryck, O.; Blanc, F.; Roger, N.; Fleury, M.; Rudolf, G.; Marignier, R.; Vukusic, S.; Confavreux, C.; et al. Is neuromyelitis optica associated with human leukocyte antigen? Mult. Scler. 2009, 15, 571-579.

80. Brum, D.G.; Barreira, A.A.; dos Santos, A.C.; Kaimen-Maciel, D.R.; Matiello, M.; Costa, R.M.; Deghaide, N.H.; Costa, L.S.; Louzada-Junior, P.; Diniz, P.R.; et al. HLA-DRB association in neuromyelitis optica is different from that observed in multiple sclerosis. Mult. Scler. 2010, 16, 21-29.

81. Matsushita, T.; Matsuoka, T.; Isobe, N.; Kawano, Y.; Minohara, M.; Shi, N.; Nishimura, Y.; Ochi, H.; Kira, J. Association of the HLA-DPB1*0501 allele with anti-aquaporin-4 antibody positivity in japanese patients with idiopathic central nervous system demyelinating disorders. Tissue Antigens 2009, 73, 171-176.

82. Wang, H.; Dai, Y.; Qiu, W.; Zhong, X.; Wu, A.; Wang, Y.; Lu, Z.; Bao, J.; Hu, X. HLA-DPB1 0501 is associated with susceptibility to anti-aquaporin-4 antibodies positive neuromyelitis optica in southern han chinese. J. Neuroimmunol. 2011, 233, 181-184.

83. Tsao, B.P. The genetics of human systemic lupus erythematosus. Trends Immunol. 2003, 24, 595-602.

84. Onuma, H.; Ota, M.; Sugenoya, A.; Inoko, H. Association of HLA-DPB1*0501 with early-onset Graves' disease in Japanese. Hum. Immunol. 1994, 39, 195-201.

85. Matiello, M.; Kantarci, O.; Brum, D.; Schaefer-Klein, J.; Weinshenker, B.; Consortium, N.G. HLA DRB1*1501 tagging rs3135388 polymorphism associated with multiple sclerosis is inversely associated with NMO. Mult. Scler. 2009, 15, S69.

86. Deschamps, R.; Paturel, L.; Jeannin, S.; Chausson, N.; Olindo, S.; Bera, O.; Bellance, R.; Smadja, D.; Cesaire, D.; Cabre, P. Different HLA class II (DRB1 and DQB1) alleles determine either susceptibility or resistance to nmo and multiple sclerosis among the French Afro-Caribbean population. Mult. Scler. 2011, 17, 24-31.

87. Stewart, G.J.; Teutsch, S.M.; Castle, M.; Heard, R.N.; Bennetts, B.H. HLA-DR, -DQA1 and -DQB1 associations in Australian multiple sclerosis patients. Eur. J. Immunogenet. 1997, 24, 81-92.

88. Mealy, M.A.; Wingerchuk, D.M.; Greenberg, B.M.; Levy, M. Epidemiology of neuromyelitis optica in the United States: A multicenter analysis epidemiology of NMO. Arch. Neurol. 2012, 69, 1176-1180.

89. Matiello, M.; Schaefer-Klein, J.L.; Hebrink, D.D.; Kingsbury, D.J.; Atkinson, E.J.; Weinshenker, B.G. NMO genetics collaborators, genetic analysis of aquaporin-4 in neuromyelitis optica. Neurology 2011, 77, 1149-1155.

90. Rossi, A.; Pisani, F.; Nicchia, G.P.; Svelto, M.; Frigeri, A. Evidences for a leaky scanning mechanism for the synthesis of the shorter M23 protein isoform of aquaporin-4 implication in orthogonal array formation and neuromyelitis optica antibody interaction. J. Biol. Chem. 2010, $285,4562-4569$.

91. Sellner, J.; Hemmer, B.; Muhlau, M. The clinical spectrum and immunobiology of parainfectious neuromyelitis optica (devic) syndromes. J. Autoimmunity 2010, 34, 371-379. 
92. Menge, T.; Cree, B.; Saleh, A.; Waterboer, T.; Berthele, A.; Kalluri, S.R.; Hemmer, B.; Aktas, O.; Hartung, H.P.; Methner, A.; et al. Neuromyelitis optica following human papillomavirus vaccination. Neurology 2012, 79, 285-287.

93. Pittock, S.J.; Lennon, V.A. Aquaporin-4 autoantibodies in a paraneoplastic context. Arch. Neurol. 2008, 65, 629-632.

94. Varrin-Doyer, M.; Spencer, C.M.; Schulze-Topphoff, U.; Nelson, P.A.; Stroud, R.M.; BA, C.C.; Zamvil, S.S. Aquaporin 4-specific T cells in neuromyelitis optica exhibit a Th17 bias and recognize Clostridium ABC transporter. Ann. Neurol. 2012, 72, 53-64.

95. Hatheway, C.L. Toxigenic clostridia. Clin. Microbiol. Rev. 1990, 3, 66-98.

96. Egg, R.; Reindl, M.; Deisenhammer, F.; Linington, C.; Berger, T. Anti-MOG and anti-MBP antibody subclasses in multiple sclerosis. Mult. Scler. 2001, 7, 285-289.

97. Angelucci, F.; Mirabella, M.; Frisullo, G.; Caggiula, M.; Tonali, P.A.; Batocchi, A.P. Serum levels of anti-myelin antibodies in relapsing-remitting multiple sclerosis patients during different phases of disease activity and immunomodulatory therapy. Dis. Markers 2005, 21, 49-55.

98. Li, L.; Zhang, H.; Varrin-Doyer, M.; Zamvil, S.S.; Verkman, A.S. Proinflammatory role of aquaporin-4 in autoimmune neuroinflammation. FASEB J. 2011, 25, 1556-1566.

99. Kinoshita, M.; Nakatsuji, Y.; Kimura, T.; Moriya, M.; Takata, K.; Okuno, T.; Kumanogoh, A.; Kajiyama, K.; Yoshikawa, H.; Sakoda, S. Neuromyelitis optica: Passive transfer to rats by human immunoglobulin. Biochem. Biophys. Res. Commun. 2009, 386, 623-627.

100. Zhang, H.; Bennett, J.L.; Verkman, A.S. Ex vivo spinal cord slice model of neuromyelitis optica reveals novel immunopathogenic mechanisms. Ann. Neurol. 2011, 70, 943-954.

101. Kinoshita, M.; Nakatsuji, Y.; Kimura, T.; Moriya, M.; Takata, K.; Okuno, T.; Kumanogoh, A.; Kajiyama, K.; Yoshikawa, H.; Sakoda, S. Anti-aquaporin-4 antibody induces astrocytic cytotoxicity in the absence of CNS antigen-specific T cells. Biochem. Biophys. Res. Commun. 2010, 394, 205-210.

102. Lennon, V.A.; Kryzer, T.J.; Pittock, S.J.; Verkman, A.S.; Hinson, S.R. IgG marker of optic-spinal multiple sclerosis binds to the aquaporin-4 water channel. J. Exp. Med. 2005, 202, 473-477.

103. Jarius, S.; Aboul-Enein, F.; Waters, P.; Kuenz, B.; Hauser, A.; Berger, T.; Lang, W.; Reindl, M.; Vincent, A.; Kristoferitsch, W. Antibody to aquaporin-4 in the long-term course of neuromyelitis optica. Brain 2008, 131, 3072-3080.

104. Hinson, S.R.; McKeon, A.; Fryer, J.P.; Apiwattanakul, M.; Lennon, V.A.; Pittock, S.J. Prediction of neuromyelitis optica attack severity by quantitation of complement-mediated injury to aquaporin-4-expressing cells. Arch. Neurol. 2009, 66, 1164-1167.

105. Matsushita, T.; Isobe, N.; Matsuoka, T.; Shi, N.; Kawano, Y.; Wu, X.M.; Yoshiura, T.; Nakao, Y.; Ishizu, T.; Kira, J.I. Aquaporin-4 autoimmune syndrome and anti-aquaporin-4 antibody-negative opticospinal multiple sclerosis in Japanese. Mult. Scler. 2009, 15, 834-847.

106. Nishiyama, S.; Ito, T.; Misu, T.; Takahashi, T.; Kikuchi, A.; Suzuki, N.; Jin, K.; Aoki, M.; Fujihara, K.; Itoyama, Y. A case of NMO seropositive for aquaporin-4 antibody more than 10 years before onset. Neurology 2009, 72, 1960-1961. 
107. Kinoshita, M.; Nakatsuji, Y.; Moriya, M.; Okuno, T.; Kumanogoh, A.; Nakano, M.; Takahashi, T.; Fujihara, K.; Tanaka, K.; Sakoda, S. Astrocytic necrosis is induced by anti-aquaporin-4 antibody-positive serum. Neuroreport 2009, 20, 508-512.

108. Kim, Y.U.; Kinoshita, T.; Molina, H.; Hourcade, D.; Seya, T.; Wagner, L.M.; Holers, V.M. Mouse complement regulatory protein Crry/p65 uses the specific mechanisms of both human decay-accelerating factor and membrane cofactor protein. J. Exp. Med. 1995, 181, 151-159.

109. Lener, M.; Vinci, G.; Duponchel, C.; Meo, T.; Tosi, M. Molecular cloning, gene structure and expression profile of mouse C1 inhibitor. Eur. J. Biochem. 1998, 254, 117-122.

110. Pinter, C.; Beltrami, S.; Caputo, D.; Ferrante, P.; Clivio, A. Presence of autoantibodies against complement regulatory proteins in relapsing-remitting multiple sclerosis. J. Neurovirol. 2000, 6 , S42-S46.

111. Vincent, T.; Saikali, P.; Cayrol, R.; Roth, A.D.; Bar-Or, A.; Prat, A.; Antel, J.P. Functional consequences of neuromyelitis optica-IgG astrocyte interactions on blood-brain barrier permeability and granulocyte recruitment. J. Immunol. 2008, 181, 5730-5737.

112. Hinson, S.R.; Romero, M.F.; Popescu, B.F.; Lucchinetti, C.F.; Fryer, J.P.; Wolburg, H.; Fallier-Becker, P.; Noell, S.; Lennon, V.A. Molecular outcomes of neuromyelitis optica (NMO)-IgG binding to aquaporin-4 in astrocytes. Proc. Natl. Acad. Sci. USA 2012, $109,1245-1250$.

113. Melamud, L.; Fernandez, J.M.; Rivarola, V.; Di Giusto, G.; Ford, P.; Villa, A.; Capurro, C. Neuromyelitis optica immunoglobulin $G$ present in sera from neuromyelitis optica patients affects aquaporin-4 expression and water permeability of the astrocyte plasma membrane. J. Neurosci. Res. 2012, 90, 1240-1248.

114. Rossi, A.; Ratelade, J.; Papadopoulos, M.C.; Bennett, J.L.; Verkman, A.S. Consequences of NMO-IgG binding to aquaporin-4 in neuromyelitis optica. Proc. Natl. Acad. Sci. USA 2012, 109, doi:10.1073/pnas.1203463109.

115. Eng, L.F.; Ghirnikar, R.S.; Lee, Y.L. Glial fibrillary acidic protein: GFAP-thirty-one years (1969-2000). Neurochem. Res. 2000, 25, 1439-1451.

116. Takano, R.; Misu, T.; Takahashi, T.; Sato, S.; Fujihara, K.; Itoyama, Y. Astrocytic damage is far more severe than demyelination in NMO a clinical CSF biomarker study. Neurology 2010, 75, 208-216.

117. Sofroniew, M.V.; Vinters, H.V. Astrocytes: Biology and pathology. Acta Neuropathol. 2010, $119,7-35$.

118. Uzawa, A.; Mori, M.; Arai, K.; Sato, Y.; Hayakawa, S.; Masuda, S.; Taniguchi, J.; Kuwabara, S. Cytokine and chemokine profiles in neuromyelitis optica: Significance of interleukin-6. Mult. Scler. 2010, 16, 1443-1452.

119. Tanaka, M.; Matsushita, T.; Tateishi, T.; Ochi, H.; Kawano, Y.; Mei, F.J.; Minohara, M.; Murai, H.; Kira, J.I. Distinct CSF cytokine/chemokine profiles in atopic myelitis and other causes of myelitis. Neurology 2008, 71, 974-981.

120. Ishizu, T.; Osoegawa, M.; Mei, F.J.; Kikuchi, H.; Tanaka, M.; Takakura, Y.; Minohara, M.; Murai, H.; Mihara, F.; Taniwaki, T.; et al. Intrathecal activation of the IL-17/IL-8 axis in opticospinal multiple sclerosis. Brain 2005, 128, 988-1002. 
121. Correale, J.; Fiol, M. Chitinase effects on immune cell response in neuromyelitis optica and multiple sclerosis. Mult. Scler. 2011, 17, 521-531.

122. Mandler, R.N.; Davis, L.E.; Jeffery, D.R.; Kornfeld, M. Devic's neuromyelitis optica: A clinicopathological study of 8 patients. Ann. Neurol. 1993, 34, 162-168.

123. Zhong, X.; Wang, H.; Dai, Y.; Wu, A.; Bao, J.; Xu, W.; Cheng, C.; Lu, Z.; Qiu, W.; Hu, X. Cerebrospinal fluid levels of CXCL13 are elevated in neuromyelitis optica. J. Neuroimmunol. 2011, 240-241, 104-108.

124. Manzo, A.; Vitolo, B.; Humby, F.; Caporali, R.; Jarrossay, D.; Dell'accio, F.; Ciardelli, L.; Uguccioni, M.; Montecucco, C.; Pitzalis, C. Mature antigen-experienced T helper cells synthesize and secrete the B cell chemoattractant CXCL13 in the inflammatory environment of the rheumatoid joint. Arthritis Rheum. 2008, 58, 3377-3387.

125. Carlsen, H.S.; Baekkevold, E.S.; Morton, H.C.; Haraldsen, G.; Brandtzaeg, P. Monocyte-like and mature macrophages produce CXCL13 (B cell-attracting chemokine 1) in inflammatory lesions with lymphoid neogenesis. Blood 2004, 104, 3021-3027.

126. Vaknin-Dembinsky, A.; Brill, L.; Orpaz, N.; Abramsky, O.; Karussis, D. Preferential increase of B-cell activating factor in the cerebrospinal fluid of neuromyelitis optica in a white population. Mult. Scler. 2010, 16, 1453-1457.

127. Mackay, F.; Schneider, P. Cracking the BAFF code. Nat. Rev. Immunol. 2009, 9, 491-502.

128. Krumbholz, M.; Theil, D.; Derfuss, T.; Rosenwald, A.; Schrader, F.; Monoranu, C.M.; Kalled, S.L.; Hess, D.M.; Serafini, B.; Aloisi, F.; et al. BAFF is produced by astrocytes and up-regulated in multiple sclerosis lesions and primary central nervous system lymphoma. J. Exp. Med. 2005, 201, 195-200.

129. Kayagaki, N.; Yan, M.; Seshasayee, D.; Wang, H.; Lee, W.; French, D.M.; Grewal, I.S.; Cochran, A.G.; Gordon, N.C.; Yin, J.; et al. BAFF/BLyS receptor 3 binds the B cell survival factor BAFF ligand through a discrete surface loop and promotes processing of NF-kappaB2. Immunity 2002, 17, 515-524.

130. Bergamaschi, R. Glatiramer acetate treatment in Devic's neuromyelitis optica. Brain 2003, 126, doi:10.1093/brain/awg140.

131. Gartzen, K.; Limmroth, V.; Putzki, N. Relapsing neuromyelitis optica responsive to glatiramer acetate treatment. Eur. J. Neurol. 2007, 14, e12-e13.

132. Icoz, S.; Tuzun, E.; Kurtuncu, M.; Durmus, H.; Mutlu, M.; Eraksoy, M.; Akman-Demir, G. Enhanced IL-6 production in aquaporin-4 antibody positive neuromyelitis optica patients. Int. J. Neurosci. 2010, 120, 71-75.

133. Farina, C.; Aloisi, F.; Meinl, E. Astrocytes are active players in cerebral innate immunity. Trends Immunol. 2007, 28, 138-145.

134. Ulusoy, C.; Tuzun, E.; Kurtuncu, M.; Turkoglu, R.; Akman-Demir, G.; Eraksoy, M. Comparison of the cytokine profiles of patients with neuronal-antibody-associated central nervous system disorders. Int. J. Neurosci. 2012, 122, 284-289.

135. Bettelli, E.; Carrier, Y.; Gao, W.; Korn, T.; Strom, T.B.; Oukka, M.; Weiner, H.L.; Kuchroo, V.K. Reciprocal developmental pathways for the generation of pathogenic effector Th17 and regulatory T cells. Nature 2006, 441, 235-238. 
136. Wilke, C.M.; Bishop, K.; Fox, D.; Zou, W. Deciphering the role of Th17 cells in human disease. Trends Immunol. 2011, 32, 603-611.

137. Wang, H.H.; Dai, Y.Q.; Qiu, W.; Lu, Z.Q.; Peng, F.H.; Wang, Y.G.; Bao, J.; Li, Y.; Hu, X.Q. Interleukin-17-secreting $\mathrm{T}$ cells in neuromyelitis optica and multiple sclerosis during relapse. J. Clin. Neurosci. 2011, 18, 1313-1317.

138. Li, Y.; Wang, H.; Long, Y.; Lu, Z.; Hu, X. Increased memory Th17 cells in patients with neuromyelitis optica and multiple sclerosis. J. Neuroimmunol. 2011, 234, 155-160.

139. Murphy, A.C.; Lalor, S.J.; Lynch, M.A.; Mills, K.H. Infiltration of Th1 and Th17 cells and activation of microglia in the CNS during the course of experimental autoimmune encephalomyelitis. Brain Behav. Immun. 2010, 24, 641-651.

140. Matsuya, N.; Komori, M.; Nomura, K.; Nakane, S.; Fukudome, T.; Goto, H.; Shiraishi, H.; Wandinger, K.P.; Matsuo, H.; Kondo, T. Increased T-cell immunity against aquaporin-4 and proteolipid protein in neuromyelitis optica. Int. Immunol. 2011, 23, 565-573.

141. Vaknin-Dembinsky, A.; Brill, L.; Kassis, I.; Petrou, P.; Ovadia, H.; Ben-Hur, T.; Abramsky, O.; Karussis, D. T-cell reactivity against AQP4 in neuromyelitis optica. Neurology 2012, 79, 945-946.

142. Nakashima, I.; Takahashi, T.; Cree, B.A.; Kim, H.J.; Suzuki, C.; Genain, C.P.; Vincent, T.; Fujihara, K.; Itoyama, Y.; Bar-Or, A. Transient increases in anti-aquaporin-4 antibody titers following rituximab treatment in neuromyelitis optica, in association with elevated serum BAFF levels. J. Clin. Neurosci. 2011, 18, 997-998.

143. Tedder, T.F.; Engel, P. Cd20: A regulator of cell-cycle progression of B lymphocytes. Immunol. Today 1994, 15, 450-454.

144. Manz, R.A.; Arce, S.; Cassese, G.; Hauser, A.E.; Hiepe, F.; Radbruch, A. Humoral immunity and long-lived plasma cells. Curr. Opin. Immunol. 2002, 14, 517-521.

145. Uzawa, A.; Mori, M.; Masuda, S.; Kuwabara, S. Markedly elevated soluble intercellular adhesion molecule 1, soluble vascular cell adhesion molecule 1 levels, and blood-brain barrier breakdown in neuromyelitis optica. Arch. Neurol. 2011, 68, 913-917.

146. Shimizu, F.; Sano, Y.; Takahashi, T.; Haruki, H.; Saito, K.; Koga, M.; Kanda, T. Sera from neuromyelitis optica patients disrupt the blood-brain barrier. J. Neurol. Neurosurg. Psychiatry 2012, 83, 288-297.

147. Roemer, S.F.; Parisi, J.E.; Lennon, V.A.; Benarroch, E.E.; Lassmann, H.; Bruck, W.; Mandler, R.N.; Weinshenker, B.G.; Pittock, S.J.; Wingerchuk, D.M.; et al. Pattern-specific loss of aquaporin-4 immunoreactivity distinguishes neuromyelitis optica from multiple sclerosis. Brain 2007, 130, 1194-1205.

148. Lucchinetti, C.F.; Mandler, R.N.; McGavern, D.; Bruck, W.; Gleich, G.; Ransohoff, R.M.; Trebst, C.; Weinshenker, B.; Wingerchuk, D.; Parisi, J.E.; et al. A role for humoral mechanisms in the pathogenesis of Devic's neuromyelitis optica. Brain 2002, 125, 1450-1461.

149. Barnett, M.H.; Parratt, J.D.; Cho, E.S.; Prineas, J.W. Immunoglobulins and complement in postmortem multiple sclerosis tissue. Ann. Neurol. 2009, 65, 32-46.

150. Barnett, M.H.; Prineas, J.W.; Buckland, M.E.; Parratt, J.D.; Pollard, J.D. Massive astrocyte destruction in neuromyelitis optica despite natalizumab therapy. Mult. Scler. 2012, 18, 108-112. 
151. Kobayashi, Z.; Tsuchiya, K.; Uchihara, T.; Nakamura, A.; Haga, C.; Yokota, O.; Ishizu, H.; Taki, K.; Arai, T.; Akiyama, H.; et al. Intractable hiccup caused by medulla oblongata lesions: A study of an autopsy patient with possible neuromyelitis optica. J. Neurol. Sci. 2009, 285, 241-245.

152. Matsuoka, T.; Suzuki, S.O.; Suenaga, T.; Iwaki, T.; Kira, J. Reappraisal of aquaporin-4 astrocytopathy in asian neuromyelitis optica and multiple sclerosis patients. Brain Pathol. 2011, $21,516-532$.

153. Lee, D.H.; Metz, I.; Berthele, A.; Stadelmann, C.; Bruck, W.; Linker, R.A.; Gold, R.; Schroeder, A. Supraspinal demyelinating lesions in neuromyelitis optica display a typical astrocyte pathology. Neuropathol. Appl. Neurobiol. 2010, 36, 685-687.

154. Tradtrantip, L.; Zhang, H.; Anderson, M.O.; Saadoun, S.; Phuan, P.W.; Papadopoulos, M.C.; Bennett, J.L.; Verkman, A.S. Small-molecule inhibitors of NMO-IgG binding to aquaporin-4 reduce astrocyte cytotoxicity in neuromyelitis optica. FASEB J. 2012, 26, 2197-2208.

155. Hutas, G. Ocrelizumab, a humanized monoclonal antibody against CD20 for inflammatory disorders and B-cell malignancies. Curr. Opin. Investig. Drugs 2008, 9, 1206-1215.

156. Herbst, R.; Wang, Y.; Gallagher, S.; Mittereder, N.; Kuta, E.; Damschroder, M.; Woods, R.; Rowe, D.C.; Cheng, L.; Cook, K.; et al. B-cell depletion in vitro and in vivo with an afucosylated anti-CD19 antibody. J. Pharmacol. Exp. Ther. 2010, 335, 213-222.

(C) 2012 by the authors; licensee MDPI, Basel, Switzerland. This article is an open access article distributed under the terms and conditions of the Creative Commons Attribution license (http://creativecommons.org/licenses/by/3.0/). 